\title{
Conceptual Knowledge Approach to Operational Risk Management (A Case Study)
}

\author{
Ali Hadi Jebrin (Associate Professor) \\ Department of Business Administration, Amman Arab University \\ Amman, Jordan \\ E-mail: daad_Ali@yahoo \\ Abdalla Jamil Abu-Salma \\ Department of Business Administration, Middle East University \\ Amman, Jordan
}

Received: September 15, 2011

Accepted: November 9, 2011

Published: January 16, 2012

doi:10.5539/ijbm.v7n2p289

URL: http://dx.doi.org/10.5539/ijbm.v7n2p289

\begin{abstract}
This research provides a knowledge conceptual approach to Operational Risk Management, in attempt to explore the scientific bases of the theoretical and practical concerns. The content of this effort is intended to establish a new approach to operations management to be set as a role model for researchers, and particularly the scientific research teams to keep pace with related companies and organizations. the researchers hypothesized that, The risk is the power should be taken into account in the industry. Secondly, Risk Management by its characteristics, is an important approach to the decisions and operation of the top management. It is an inclusive process with all other activities of the whole company. "Performance, scheduling, cost and product life-cycle". Thirdly, Risk Management has two main basic building blocks: The organizing of the operations and the knowledge-associated support system (Decision Support System).

This research also aims to teach the organizations a method to detect and process the data and information by the Risk Memory tool, through their epistemological networks which are connected by Decision Support System within the framework and the aims of the organization (Theory-In-Use).
\end{abstract}

Keywords: Project management, Risk management project, Knowledge management operational, Decision support systems, Organizational process

\section{Introduction}

The morals of the Operational Risk Management have always been characterized as they give the "Risk" part the most importance, this, along with the western culture, have led to the concern of the "Risk" part as it is the most important element.

The common effect of the knowledge theory (Epistemological) ignited researches to distinguish the companies that study the "Risk" and it is implementations which associated with knowledge and Decision Support System (DSS).On the other hand the companies that depends on the organized work. Thus, an knowledge conceptual approach to Risk Management has emerged.

Based upon that, this research seriously considers the analysis of the companies' problem in dealing with the Operational Risk Management subject .And the Risk is meant to be the essential key towards these solutions. The scientific researchers plays a key role in "Designing the Risk" to show the headlines for the companies and organizations to deal with these problems, especially in the early stages of the product/service since there are the core elements of the cognitive origins to manage the Risk particularly, and the whole organization generally.

This paper discusses the utilization of The Risk Management Corporate Memory (RMCM) in Decisions Support System to avoid the dangers as much as possible, to get the Best Final Offer (BFO) for the product/service .This is a very important goal that no company today should hesitate to look for tracks to follow it.

\section{The Research Methodology}

This chapter describes the research methodology which contains: First, its importance and its goal, and secondly, expressing its problem and hypotheses and at last, the researches' procedure and its way. 


\subsection{The Importance and the Goal of the Research}

The Risk subject is significance an important concept due to the fact its influential effect on the actual work of the companies.

The Researchers believe that the developing countries are still facing problems coming from a distinct lack of Risk and Risk Management and its role in industrial and services companies to be the motivation the benchmarks that can be used by companies in these countries to find their competitive position.

Accordingly this paper provides a knowledge conceptual approach to Operational Risk Management, in attempt to explore the scientific bases of the theoretical and practical concerns. The goal is establish a new approach to operations management to be set as role model for researchers, and particularly the scientific research teams to keep pace with scientific research with related companies and organizations.

This study present a new method to organize the production process that focuses discusses on the Risk Management for the organizations, to secure the knowledge assets, especially in the early stages of this process according to the concept of the (Espoused Theory).

This research also aims to teach the organizations a method to detect and process the data and information by the Risk Memory tool through their epistemological networks which are connected by Decision Support System within the framework and the aims of the organization (Theory-In-Use).

\subsection{The Problem and the hypotheses of the Research}

The Problem of this research is shown as we show the importance and the aims of its treatment as it was stated in its introduction and importance. And then we see it centered on the nature of the challenges faced by today's' organizations. These challenges were created by the accelerating changes of the risk concept emergence and risk impact. In this particular curve with the concept of the "Risk Management", it was found appropriate to highlight the mechanism of an educational_conceptual approach of the Risk Management to encourage the ideas that call for creative potentials and capabilities. Believing that the increasing usage of knowledge change this subject towards an Procedural operational management by the philosophy of the perspective of the operational Rationality, based on a role-model approach for the researchers in the field of Risk Management to form a more-efficient database in explaining and identifying the produced creativity to meet the market needs and consumer desires.

To deal with what we have presented and described as a problem and the importance of this research, we have built hypotheses as the following:

First Hypothesis: The risk is considered the power and the case that should be taken into account in the industry events and activities.

Second Hypothesis: Risk Management by its characteristics, is an important approach to the decisions and operation of the top management. It is an inclusive process with all other activities of the whole company. "Performance, scheduling, cost and product life-cycle"

Third Hypothesis: The Risk Management has two main basic building blocks: The organizing of the operation and the knowledge-associated support system (Decision Support System).

\subsection{The Methodology of the Research}

Two main groups of scientific researchers were using deduction and induction methods to build and form a conceptual approach to be considered as a main system that could be an evidence to explore and process the production operations through ensuring knowledge fundamentals, especially in the early stages of the operations, in the range of interpretations, which does not deviate from the rules of the objective scientific research.

This research focuses on the following points:

2.3.1 The research requires a project called an approach to the operational risk management, to addresses the issues that would be discussed under the operational risk management and decision support system.

2.3.2 The Implications of this approach and their relationship to managerial hypothesis that will be addressed by the research.

2.3.3 The Effects of the risk management on the corporations, is an appropriate sign to describe a case study of a sample of three construction Jordanian companies to represent these_effects with respect to the main aims of this research. And we did not want to add the competition prospects because of the modern morals of the "Case Study" and "Field Study" methods. But we did not succumb - in the range of our knowledge- to systematicallyprocess the implementations of this study. 
2.3.4 An attempt to probe the scientific fundamentals of the theoretical and practical research keys, which are: project management, risk management, knowledge management, decision support systems, operational decision-making strategy (organizational process).

Accordingly, we found that it's very appropriate to arrange the subject as discussing the following fields: Introduction.

1) The Research methodology.

2) Operational Risk Management Project.

3) The Tends of the organizing and management hypothesis by Risk Management Project.

4) A Case Study.

5) Conclusions and Recommendations.

\section{Operational Risk Management Project}

\subsection{The Early Operational Stage}

The Creativity Theory does not focus on the processes that come before inventions and creativity, (Bennett, 2005). However, Schumpeters in his theory in economic growth emphasizes on the importance of the efforts that comes after the creativity to the implementation, which generally concerns about the sequence of events and developments following the emergence of the idea until it comes into existence (Herald, 1995).

Based upon that, the purpose, the time and the resources are considered important management tools to be in the project management (Florida, 1993). We could mention here that representation of the projects, even It was build on high levels of certainty about its' outcomes, it is still open for debating and discussion. It is appropriate to propose that the project management operates in a world of a mess and confusion, so, it is highly- expected that knowledge plays a key role in the Risk Management, therefore, the administration could be under increasing pressure (Darenport, 1998) especially at the early stages of the project.

The most important point, as much as it is connected to our main problem, is to set a concept that focuses on the early stages of the project. indicates the beginning and the implementation of the project in a classic approach that focuses on the operations, the executive activities and the goals of the project. Figure 2

It is well-known fact that through this stage, some undesired stuff will show up, along with some executive activities (like debates and controversial goals-setting) with some epistemic concerns(Chapman, 2007), which causes some chaos in the classical project morals, and that what gives the risk subject and its Management additional special significance.

The initial stages of the project according to Systems Theory have been generally looked at as a group of compound-structure elements that represents (Plan, Control and Evaluation). This idea (Hargreavers, 1989), has a counterproposal that considers the projects are just "Temporary Organizations" (Packendroff, 2003). Weick agrees to this proposal which assumes that "Alternative Assumptions" includes the scheme of the project based on individual concepts (Weick, 1979).

This operational rational challenge for the organizations (as they are Temporary Organizations) strengthens the theory that refuses the capital and work as they are the basic foundation of the economy, and focuses on a more-Radical form according to Biosots' concept, that mentions the increasing importance of the knowledge as he focuses on the data and information that creates Information Space (Camillus, 2009).

\section{2 approach to the Risk Management Project}

This Introduction aims to present a conceptual frame for the decision- makers to attain a procedure to discover the information systems within the organizations' knowledge base, or through the risk's linked memory, especially Decision Support Systems and administrative hypotheses. Which is based on the conception of the Theory-In-Use (Holsapple, 2005).

This approach of the Risk Management project is based on certain tools and elements mentioned as follows:

3.2.1 The Risk is based on operational approach by Risk-Designing, and it's an effective activity that focuses on the early stage of the product life-cycle (Davenport, 1993).

3.2.2 This operational rational challenge for the Approach Risk Management strengthens the theory that refuses the capital and work a foundation of the main operations in free-economy to benefit from the knowledge (Holsapple, 2005. p.7). Instead, it insists on the Risk Memory (RMCM) which supplies the administration with the data and information needed to create Informational Space that directs the knowledge through the early operational stages. 
3.2.3 The Decision Support System (DSS) is the key to choose the best way that operates to get the Best Final Offer (BFO).Emphasizing on what presented previously, ideas and figures; we found an appropriate frame that reflects visions on the operational risk management fields that allows the top administration to research comprehensively about operational and administrative subjects within the knowledge data base that forms from approach to Risk Management to achieve a way through operational-decisions sorts shows the previous approach. Figure (3)

Within this frame, and based on the previous figure, a need to strengthen some basic concepts that this project "Approach to operational risk managements" as follows:

3.2.4 Operational Risk Management: If the organization wants to define an operational goal, it must apply and pay attention to this project, with all of its contents of tools, represented by "Evaluating the Risk" and an high levels as the tool to support the decisions and the strategy of the organization in which belongs to products, and every product got its' own life-cycle.

The Risk Management project adopts multi-dimensional analysis based on controversial economic methodology emerged from the Risk Memory, that represents a group of applicable suggestions, especially on the initial early stages, and then forms a suggested operations that's aims to discover and develop advanced recommendations on the producing field.

3.2.5 The other principle that project of Approach Risk Management depends on, is to represent evaluations for the internal risk (productions, operations, resources and coasts) and the external risk (customers, consumer, market, competition, environment, law and order) and its advantages and disadvantages. Despite the difference in its variables, it still depends on each other in the concept of the operations standards.

3.2.6 The Risk Management is associated with Risk Memory (RMCM), and it is considered to be controlled by the approach, which based on reusing the actions that faces the Risk. This tool is important because it helps discovering data and information within a special database that the corporations' memory is built on a group of connections according to the theory of existence by reorganizing the operations, and it is considered to be the best used tool that managers and workers use to learn by experience and as a practice.

3.2.7 Operational/process knowledge is the dominant knowledge which is organized by Decision Support System when it comes to Products, Costs and Risk.

3.2.8 Decision Support System (DSS) is another tool that depends on computer systems, and it is an interactive system that helps decision makers using the data and the forms in cost goals, price and risk (Davenport, 1998, pp.16-17), and it is programmed by sharing and RMCM systems inside the organization.

\section{The Tends of the organizing and management hypothesis by Risk Management Project}

The Approach of the Risk Management project raises a modern vision to contribute the organizing and administration theories that suits new methods of concept and theory. Each one is considered as a key to the competitive case of companies and organizations. These cases establish the best way of both leverage and efficiency as it is in "Step by Step Change" (Bennett, 2005, p.44).

Based on that, the corporations need the following: (a) to be aware of the potential knowledge, because of the shortage in sharing between the managers and the workers. (b)to Focus in operational chaos process, and on the strategic decision making.(c)the Efficiency of the strategic decision making.

The hypotheses are formed within a vision that fit the organization needs, and prepares a vision that helps the Risk Management to diagnose the risks on the long-term direction to create its own business center.

The previous concentrated presentation leads to diagnose the general features of these hypotheses as follows:

\subsection{Risk and Risk Management}

The project of an approach to the Risk Management, best known for its characteristics which give it the focus on the major cases in business activities, while it's specified by data from: (a) Utilizing the chances, in addition to facing the risks and the generating threats.(b)Evaluating the Internal and the external risk, and analyzing the inner plans using the control operations and specifying the variables to form the internal and external risks.

The risk management through the Risk Management project focuses on the early stages of the production (as it's been previously confirmed) and its range of motion is more efficient in creativity, renovation and changing which leads to an administrative change, a more inclusive and realistic change, with business indexes and on a high-level decisions.

It is importance is associated with its dependence on an inclusive perspective to achieve the goals and eliminating the dangerous problems those face the operations. 
The happening evolution in the organizations has obligated the administrations to think by the scientific logic (Packendroff, 2003, p.328) to manage the risk and their own internal environment for any risks, and analyze their external environment and all the series of risks and challenges. It was confirmed by the European Committee for Standards in its publication about protecting the corporations from dangers.

The instructors of this concept were trying to present relating subjects like "Designing the Cost" until the Risk Management was in developing process (Michaels, 1989).

The project of an approach to the risk management presents the definition of the risk as a completely developed concept to operations and evaluating the projects that focuses on the constructive nature of interactions from associated multi-dimensions to include the fields of "environment, performance, scheduling and profitability". And This the second hypothesis of the methodology of this research that is to, extend to products, markets, customers and the major policies that the corporation need to achieve its goals, especially at the early stage of production to meet up the needs and desires of the consumer.

A Theory includes technological memory to know the products and industrial operations.

\subsection{The Knowledge Management}

The interest in knowledge in the western culture came from the Alcmaeons, the Empedocles and the Democritus, and the word "Knowledge" is a common nowadays, and the knowledge society is using it to insist on its significance. Drucker defined it as it's the most important source in the industrial society field (Drkcker, 2006). Romer considered it an important source to the leaders and their consultants in the organizations and the essential key in competitive trail (Roman, 1988).Researchers began to discriminate between organizations that depends on the knowledge and the organizations that depends on the capital, like Reick, Prahaled and Hamel (Reich, 2010 and Prahaled, 1998), and in this period a new concept emerged, the knowledge factor as Zuboff mentioned, (Zuboff,1998).

The location of producing knowledge is no longer limited to search groups and education as, it is relocated organizations and other companies now.

The focus is now more on forming the knowledge as administrative operation by practical instructions in between all kinds of people. This change is reflected on the transformation of the decision maker and the Dicision Support Systems as a fundamental tool in (WIP) in addition to decision making about the final product as the (Espoused Theory) mentioned.

The common belief of Traditional rationality model changes this situation towards operational management is being represented as the philosophy of procedural rationality perspective which depends on supporting the design of the new operations, like designing the cost. This leads to decisions that can be followed in Risk Management, which can also be called Knowledge of the Decision.

The main goal of this article is to present project of an approach to the Risk Management aims to teach and introduce the concepts to the groups and persons in the top administration to achieve a method that discovers information systems within the corporate epistemic data base of the organization through its knowledge corporate network as in Theory-In-Use concept.

The Knowledge Management Concept in the project of an approach to the Risk Management is based on essential points:

4.2.1 it is directed into the business knowledge and the managers needs, as it helps the organization diagnosing the actions that causes future problems and easing setting goals and associated memory directions day by day, besides helping managers to deal with weak standards and guaranteeing rational that classifies the resources and supply the corporation with synergetic internal consistency.

4.2.2 It depends on forms of leading roles and on leading jobs that associated with persons as Argyris (Minzberg, 1994), mentioned. it seems that the knowledge management concept in the Risk Management approach is an influential leading culture on the workedrs by a group of tools that works as instructions in project management.

The knowledge management requires administration in the organization to ease achieving the information, and reusing it, and this can be achieved by using advanced information technique. The knowledge management is considered a scientific-method related because the knowledge is classified upon the science of existence (Ontology) that based on constructions, known as expert systems and knowledge- dependent systems, case study system, data rules. etc. whereas the computer uses a database to answer the investors questions (Nonaka, 1995).

The memory analysis enclosed the approach upon rational design "Composition of work teams ", and the memory of Finance, to see" Analysis of budget, costs and manpower, financial results, "memory and internal risk, knowledge regarding the" insurance, booking, risk the existence of technology, a new, risk management, 
risk contractors and finally the memory of price, knowledge regarding customers, competition, market, market strategy .

The project of an approach to the Risk Management deals with knowledge management from its fundamental formula, as a method that supplies the organization with the Tacit Knowledge for persons, groups and the organization itself, and this has been mentioned by Christensen.

\subsection{Decision making}

Managers take many decisions on daily basis, and their success depends on this operation, but the obstacle that they face is the cost. The project of an approach to the Risk Management mentioned that point, and consider it a very sensitive and very important to the companies. The managers capability to diagnose and define the diemntions in what surrounds the organization is the ability to take a decison, especially if the knowledge is available, and vice versa if the knowledge is not. the risk takes apart in decision making ;some of them are:

4.3.1 Operational Risks: products, operational processes, costs and sources. But the processing is done by RMCM tool.

4.3.2 The approach is run in sequence of steps and stages the approach does it, and the managers and workers adopt them to guarantee the rationality of form building which leads to decreasing the Risk situations.

4.3.3 A Change in information processing to build rational evaluation.

4.3.4 A Difference between internal and external knowledge.

The approach also categorizes the solutions for the managers while they are handling risks and various problems according to administrative levels (Top, mid, Bottom) and the decisions for each level are the tactical, strategic decisions.

\subsection{The Management process}

The project of an approach to the Risk Management is considered a work proof for the management process, and re-engineering the process operations. It's based on:

4.4.1 Re-unify the foundations of the organizational operations and administrative theories. Or:

4.4.2 It works within the "step-by-step" change approach concept in the organizational operation. Also, the (RMCM) tool is an important tool in changing and adopting the new work operations. Meaning that the operations are heading towards building a business organizational change aiming to issues the consumer's products in regulation with (BPR).

The management process in the project of an approach to the Risk Management is based on two primary specifications. They are:(a) visions for the organization that aim to stop the problems facing the organization and the productive units.(b) the foundation to achieving the consumer's needs and convictions. It is considered a guide to achieving organizational functions and the importance operation to achieve the aims.

The "step-by-step" change approach confirms a new concept in the organization, and a dramatic achievement with the purpose of improving the organization's results in the practical goals "Quality, time, benefit, and reliability". Applying this approach is considered effective (applying the right things), and an answer to the competency and the creativity questions (Do things in the right way), although, it's facing some trouble fitting in, due to the current organization or the workers disapproval.

The form issued by the introduction is called the "Explicit knowledge". And the form the "approach" presents allows explicit knowledge, as well as sharing between the workers and the managers to help them separate operational and the decision making processes.

However, the competitive thinking demands the contribution of the administrative process in the organizational process towards developing certain activities, and building a linking bridge in the organization's strategic work path.

The administrative process is presented with information that offers a clear view to improving the work processes' points of view. Furthermore, it is the "key" the mangers are entrusted with.

In spite of the fact that the previously stated goals are considered important points in the administrative and organizational operation, and a valuable asset to the evaluation. the "risk management" approach project confirms the risk and categorizes it as the important case and a priority in the manager's work, which in turn makes it valuable to the operations. It matches the first theory within the research methodology that indicates "Considering the risk, and the case taken into consideration in the activities, and the industrial activities". 


\section{A Case Study}

In what follows, we will show the outline borders for the case study based on the foundation of combining between the knowledge in the research institutions, and the available knowledge in the companies seeking development. The experiment was developed with the estate bank's loan funding for the Jordanian structural industries endorsement. The experiment was conducted on a group of (7) high education students from various fields. The work method used was a scientific research, alongside members of three different companies in the structural and equipment manufacturing field (8-15 members). They were assigned to conduct specific creative assignments in the early stages of the production. The companies seek to develop the product, and transfer the knowledge into an economical value.

The group worker under the umbrella of knowledge operations management, with the management through ensuring the knowledge aspects of the early stages of production. Furthermore, in this stage, the easily obtained knowledge and the decision outcomes based on that knowledge diverge and differ.

The existence of various proceeding activities, formalizing uncertain goals, and planning of typical issues that brings risks like uncivilized conflicts, become clear.

Projects and activities are taken into considerations with a high amount of precision, such as debatable, (Temporary Organization projects), that are faced with disturbances due to the lack of knowledge. However, research factors have been used to identify the factors that helped or held back the creative capabilities.

Our role was to follow through the products starting from ideas leading to an advanced stage of innovation. The work took the form of meetings, with outsider observers through, and documented the operations using recordings, video, and post notes. Professionals from the Operational management have been hired, which we call "espousing theory". Information and date were searched for in the company's knowledge database through interconnected networks according to the theory's understandings in application. The administrative extremeness started to escalate through formal communications, based on the companies' suggested standards. Therefore, many suggestions emerged concerning the risk factors in one of the companies. The same thing happened to the other two as well.

We were part of an advanced project management and creativity seminar. The application of feedback was the followed procedure between the research institutes and companies. Also, we gained knowledge concerning a number of systems facing cases of chaos and instabilities.

The approach of the risk management project was used, which as we stated, is a normative project specially developed for the early stages of the temporary organizations, and it is based, theoretically and practically, on foundations and tools. Furthermore, this project was tested in the Middle East University. At first, chaos was part of the project's management protocol that was functioning in the last couple of years as a part of the operational system. The operations and the working activities in managing this project are based on a strong database. The (RMCM) system was used to obtain the needed knowledge to adjust the cases of confusion. However, we observed a difficulty in adapting with most of the facts and information. The first issue of the product was completed, and the product's cost was a problem. that is based on the fact of the cost's elements system, and its organization in the memory.(EXCEL) was used to assess the total cost by using a specific program called (PRICE), which is currently used in many countries of the European Union to deal with risk assessment generated from problems at work in the early stages. From the initial results shown by (RMCM)'s memory assessment date in the risk management project. We found that one of the main reasons in the cost deterioration, specifically in the early stages, trace back to the risks from the following:

- Used technology: What is new in technology? bad assessment of the operational activation requirements, consequences of having primary solutions.

- Mission diversion: Not having a pattern in the process standards, excessive usage of contracts, data organization.

- People: Bureaucratic organization, fabricated behavior, automated adaption, Weakness in building programs and finding solutions.

- Conflicts: assigning goals and their conflicts between the stakeholders, competition, Diversion from work, objectivity in assessment.

- Management: Financial instability, lack of opportunity, reuse of former experience, incomplete theories.

- Cost: Weakness in determining its source, quality of the product. 
The operations based on the memory system and (EXCEL) were re-organized. One of the personnel in the research group found out that the knowledge issue and its management played an essential role in having the risks occur. Furthermore, risk managers were found to be using old methods.

The practical application for the approach of risk management project helped the research team to fulfill practical achievements in the operational and decision making field. And the initial positive outcomes were perceived by the inspecting companies, especially in the early productive stages of its productive work for the new term, specifically on the short-term of reducing the cost risk levels.

However, on the long term, the plans are made upon the foundation of rephrasing the organizational operation, and controlling the administrative operation, as well as describing its hypothesis and organizing the decision making operation and the style of building organizational structure. And all of that requires doing another research.

\section{Conclusions and Recommendations}

\subsection{Conclusions and perceptions}

\subsubsection{Perceptions}

It seems that the constant critic concerning the suggested ideas for handling the company's risks, work teams, and crisis, Although it generally heads towards establishing clear projections that limit any weaknesses and symptoms in outcome, if it wasn't unanimously agreed upon to have certain methods in the creative operations for the company's problems despite of the unanimous decision of the need to choose an input for risk management. It was discovered from the practical and theoretical debates with practical denotations the possibility of launching perceptions that the method of operation of the early stages is an inclusive concept that handles ideas for continuous improvement operations. And that the knowledge is the goal of decreasing risks as well as the creative operation.

The following table (1) contains the outlines for the methods of the suggested work, which can be a practical option justifying choosing the early stage for temporary projects.

Following the analysis of what was presented in the previous table, two aspects emerge. First of which indicates the structure representing a familiar method to project owners. However, this method lacks certainty and/or goals that make a rational option difficult to execute. Also, its leadership is characterized with the lack of transparency, and that the knowledge is implicit, and the information is external.

The second aspect however is important due to its vision towards the early stages; hence, it is one of the most effective work methods in management operations, and the collaboration theme between the companies and the scientific research centers and work teams.

The collaboration between those parties is the effective rational behavior in the operational risk management to achieve the knowledge exchange which is clearly expressed through scheduled meetings and reports. What is important here is the realization of the need to change a goal-oriented form into an operational rational module that adds administrative transparency; and this is our new method, which grants us the opportunity to follow through and produce the cumulative knowledge, and transfer it to the companies, as well as the educational organizations?

\subsubsection{Theoretical Review conclusions}

- According to the systems' theory that the project's first stage is a group of interconnected elements that represent the whole (plan, control, and evaluation). This is opposed with a vision that perceives projects as temporary organizations (Expectations, work/procedure, and education). This operational rational, traditional challenge for the organizations that labels them as temporary organizations enhances the theory refusing the importance of the capital, and work, in economy, and focuses on a more radical perception of the increasing importance of knowledge, as well as the data and information through which a knowledge field is created.

- $\quad$ The huge influence for the (Epistemological) theory contributed in having so many studies and research a distinctive between the companies that are based on risk studies and its applications linked to knowledge and decision theories, and the companies that depend on work organization. It contributed a new Conceptual knowledge Approach to Operational Risk Management

- This approach aims to present conceptual frame for all who is involved, as well as the decision makers, to achieve a style in discovering information systems in the organization's knowledge database, or form the interconnected risk memory through various methods. 
- The risk is based on a practical approach in "Risk design", which are the effective activities in managing risks; it focuses on the early stages of the product's lifecycle. However, the easily - accessed information and the decision outcomes based on it all differ and diverge.

- This rational challenge in the risk management approach enhances the theory refusing that the capital, and work, are one of the most important functioning operations in the economy. It also focuses on (RMCM), and in turn, it supplies the management with the needed data and information through which an informative field is created, which is directed into the changes in knowledge and its flow through operational stages and conditions.

- The development's outcomes occurring in the organizations forced the administration to consider using the scientific logic in risk management to assess its internal environment and the risks involved, as well as its external environment and everything that follows, like discovering a series of risks and challenges. This was confirmed by the European Standards Union in the publications of the proposals and recommendations in protecting the organizations from risks and dilemmas, which in turn encourages dealing with the aspects and scientific understandings for the risk, included within the standards suggested by the union.

- Change the location of the knowledge production; it was related to the education and research organizations. However, the knowledge production is not limited to the organizations; it has reached other companies and organizations.

- The main focus is shifting towards understanding the knowledge formation as an management process with practical directions between the public, taking into consideration their differences in backgrounds and concepts related to their work field. This shift and it is application is reflected on the decisions and the decision support systems. It is a primary subject in "Work In Process", as well as decision making about the final product according to the concept of the "Espoused theory".

- The common belief that the rational wisdom concerning this subject towards an procedural operational knowledge administration is best summarized in the philosophy of the operational rational perspective which is based on backing up "as a cost design", and issuing decisions that help in risk management, which can be called decisions $\backslash$ knowledge decisions.

\subsubsection{Methodological structure conclusions}

- The subject of risk gets a great deal of importance, that is clearly reflected to the actual practical work done by the companies, not just by what was presented from researches and studies done by experts.

- The researchers think that the developing Countries still face problems originating from the lack of a clear risk management, and its role to the industrial and service companies. It would be the motive towards revealing the path the companies can go through to find its competitive spot.

- This study helped presenting as a trial to incorporate scientific methods with the theoretical and practical interests. The goal of this target is having a new approach in operational management, that other interested people and researchers, especially research work teams, would look up to in an attempt to keep up with the scientific research with related companies and organizations.

- This study has achieved a new method for organizing the organizational productive operation concerning risk management to provide the knowledge origins, especially in the early stages according to the "Espoused theory". This study also aims to teaching the organizations the method of discovering and processing information and various data, through the tool of risk memory systems, or through its knowledge networks related to the decision support system, according to the organizations "Theory-in-use" goal, and projections.

- The paper only recognizes the productive operation processing through having knowledge origins, especially in the early stages of the operations and the ability to have it in the application process to test an experimental practical condition for three Jordanian corporations.

- We can further aid the previous assumption through testing the study model. This in turn contributes to giving a practical frame for the decision maker in the studied companies to process the issues with high importance in building a competent administration generally for operations, and specifically for risk management.

- In order to reach accurate outcomes that serve the goals of the study, and test its theories, the study has agreed on certain tools, verdicts, and methods in the field of computer and knowledge technology, with the usage of (EXCEL) and (PRICE). 


\subsubsection{The basic conclusions of the study's practical aspect}

- The study confirmed the possibility of testing and applying the "approach to risk management" project with all that it includes tool-wise, like the "risk evaluation". And in the top levels, a tool supporting the organization's strategy and administrative decisions concerning its products, and that every product has a lifecycle.

- $\quad$ This project adopts -according to an argumentative, technical, and economical method- multi dimensional analyses that is targeted from the memory tool. It presents with a group of applicable suggestions, especially in the primary early stages, which in turn forms suggested applications that aim to discover and develop guidelines and advices in the productive field.

- The study came up with the fact that the connection between risk management and memory, which is considered one of the tools that are controlled by the introduction, is based on the re-usage of endangered operations.

The importance of this tool lies in achieving a method in discovering data and information within a specific knowledge database, and that the organization's memory is based on a group of connections according to the "existence theory", and it gives them experience.

- The "approach to risk management" project has a contemporary vision for all of the organization and management theories. Those theories get along with new methods in concept and theory-wise. Each and single one is considered the key to the company's competitive case. Those cases aim to achiev the best way in effectiveness and efficiency, all within the "step-by-step change method".

- The "risk management" project approach a definition for risk as a whole concept for business and assessing projects. It focuses on the nature of certain interactions from different dimensions, to include fields such as "environment, performance, scheduling, and profit". This is what the second theory pointed at, to reach the products, markets, customers, and main policies needed by the organization to reach its goals, especially in the early stages of the production, to achieve the customer's desires and needs.

- This study also revealed that the "risk management" approach project handles knowledge management from its primary "formula", considering it as method supplying the organization with the tacit knowledge for people, groups, and the organization itself. After that, a rational operation which is goal-related takes place, and the outcome is the product(s).

- The "risk management" approach project is considered a work evidence for the administrative operation as well as the re-engineering of the work operations. It re-standardizes the foundations of the administration's theories and organizational operations, or works as a part of the change introduction concept such as "step-by-step" in the organizational operation. RMCM plays a vital role, as it is what changes and, at the same time, adopts the new work operations. Meaning that the operations contribute in the organizational change in business, which aims for having the consumer product in regulation with (BPR).

- The "step-by-step" change approach confirms a new concept in the organization, and a dramatic achievement with the purpose of improving the organization's results in the practical goals "Quality, time, benefit, and dependency". Taking this approach is considered very effective ( applying the right things), and an answer to competency and creativity questions (do things in the right way), and the form the "introduction" presents allows Explicit knowledge, as well as sharing between the workers and the managers to help them separate operational and the decision making process.

- The "risk management" approach project confirms the risk and categorizes it as the important case and a priority in the manager's work, which in turn makes it improve the operations. And that matches the first theory within the research methodology that indicates "Considering the risk, and the case taken into consideration in the activities, and the industrial activities".

- The outcomes of the practical application of the model for the concerned companies revealed a problem of "product cost". This is due to the organization of the cost elements, and their organization in the memory. And upon using (EXCEL) through (PRICE) to process the risk analysis, the results of (RMCM) showed that one of the main reasons of cost failure, especially in the early stages, trace back to the following:

- Used technology: What is new in technology, bad assessment of the operations requirements, consequences of primitive solutions?

- Mission change: the lack of a pattern in the operational standards, and excessive use of contracts, data arrangement.

- People: Bureaucratic organization, uncivil behavior, electronic adaptation, weakness in building programs and finding solutions. 
- Conflicts: assign goals, and their conflict between interested parties, competition, skewing at work, and subjectivity in assessment.

- Administration: financial instability, lack of opportunities, re-use of past experience, and incomplete theories.

- Cost: weakness in knowing its source, product quality.

In order to reach accurate indicators, the operations have been re-organized according to the memory system and (EXCEL).One of the working people in a research group found out that the subject of knowledge, and its management, had a primary role in having the risks occur. He also found that the risk managers still use old-assumed methods.

\subsection{Recommendations}

In continuation of the necessities of the field study, this paragraph will handle a group of recommendations and suggestions:

6.2.1 The practical application of the "risk management" approach has helped the research teams in achieving big operational achievements in the field of practicality and decision making. The first positive signs witnessed by the companies, especially in the early stages of its productive work, are lowering the levels of cost risk. However, on the long-term, the plans are put on the foundation of re-organizing the organizational operation, controlling the administrative operation, describing its theories, and organizing the decision making process as well as the system of building organizational structures. Further research is needed.

6.2.2 In support of the previous point, the categories of the "approach" were need to give solutions to the managers while handling risks and various problems. It all differs according the administrative levels (Top, mid, bottom), and the decisions at every level.

6.2.3 The study recommends the importance of taking this scientific method and studying it, because it is beneficial for the management process and the re-engineering of the work operations. It's based on, (a)Re-standardizing the foundations of the administration's theories, as well as the organizational operations,(b)Work within the "step-by-step" change approach concept in the organizational operation. The (RMCM) is the tool that does the change and, at the same time, adopts the new work operations. Meaning that the operations head towards building an organizational change for the business that aim to have the consumer's products in regulation with (BPR),(c)The organizational operation within the "risk management" approach project is based on two primary specifications:(i) It has visions for the organization that aim to stop the problems facing the organization and the productive units.(ii) it is the foundation to achieving the consumer's needs and convictions. It is considered a guide to achieving organizational and operations.

6.2.4 The importance's of the difference and the scientific research fields have been confirmed. They serve a primary role in achieving "risk design" to outline the company's, as well as the production organizations, handling direction. especially in the early stages for the activities and affective works from the product's lifecycle, since it is the foundation in offering knowledge origins for risk management in particular, organization in general. The risk memory tool system connected through the decision support system (DSS) methods give the opportunity to supply basic information at this stage, and avoid risks as much as possible. This in turn achieves the best outcome for the service/product.

6.2.5 The study confirms the importance of teaching the organizations the style of discovering and processing data and information through the "risk memory" tool, or through its knowledge networks that are connected through the DSS methods, within the organization's projections and "Theory-in-use" goals.

6.2.6 It should be mentioned that the rational challenge for the "risk management" approach enhances the theory refusing the capital and the work being one of the most important foundations of the process operations in the free economy. The idea is countered with a vision that states that projects are only temporary organizations (Expectations, Work/Procedure, and learning). This demonstrates that adjusting assumptions include studying the project based on individual concepts.

6.2.7 According to the results, the study recommends taking into consideration the following:(a)DSS is another tool that relies on computer programs. It is an interactive program that helps decision makers using data and models in cost goals and risk programmed in relation (RMCM) inside the organization.(b)Assess the internal and external risk, and, analyze the internal preparations, benefiting from the monitoring operations.[ Also, limiting variables is a model of establishing risk management; internal and external.](c)Defining risk as a whole concept for business and project assessment. [It focuses on the nature of compound interactions from different related dimensions, to include "Environment, Performance, scheduling and cost" fields.](d)Using advanced information techniques methods. Knowledge management is considered a scientific method because the information is 
classified based on the theory of existence (Ontology). [Reassigned in structures and credits in the knowledge data, to be used within expert systems,] [systems that are dependent on knowledge and database, and case-building systems]...etc. Where the computer uses certain criteria in assuming answers to the questions.

\section{References}

Bennett, Charles. (2005). "Logical Depth and Physical Complexity", in: Rolf Hearken: The Universal Turing Machine. A Half-Century Survey, Oxford University Press, Oxford. P.41.

Chapman. C., and Ward, S. (2007). Project Rick Management Process: Techniques and Insights. John Wiley and Sons: England, P.56.

Darenport, T.H., and Prusak. L. (1998). Working Knowledge - How Organizations Manage What They Know. (Harvard Business School: Boston). P16.

Davenport, T. H. (1993). Process Innovation: Reengineering Through Information Technology. Harvard Business School Process: Boston, P.16-25.

Drucker, Peter, F. (2006). Post-Capitalist Society. Butterworth-Heinemanh, Oxford., P.23.

Florida, R., and M. Kenney. (1993). The New Age of Capitalism: Innovation Mediated Production. Futures (Jules-Aug), P.309.

Hargreavers, Heap, S. (1989). Rationality in Economics. Basil Blackwell, Oxford. P.12.

Herald, Henrik. (1995). "KUBUS”, Report N .130, Business School, P.19.

Holsapple, C., and Whinston, A. B. (2005). Decision Support Systems: A Knowledge - Based Approach, Chapter 16, (West Publishing: Minneapolis). P.7.

Michaels, J.V., and Wood, W. P. (1989). Design to Cost. Wiley: England, P.12.

Minzberg, H.G. (1994). The Risk and Fall of Strategic Planning. The Free Press: Ohio, P.94.

Nonaka, I., and Takenchi, H. (1995). The Knowledge Creating Company How Japanese Compaines Create The Dynamics of Innovation. Oxford University Press, P.56.

Packendroff, Johann. (2003). Inquiring in to the Temporary Organization: New Directions for Project Management Research. Bergamot, UK, P.328.

Prahaled, C., and G. Hamel. (1998). The Core Competence of The Corporation. Harvard Business Review, May-Jun.

Reich, R. (2010). The Work of Nations: Preparing Ourselves for 22st-Century Capitalism. Simon and Schuster, London, P.2.

Roman. D.D. (1988). Managing Project: A System Approach. Elsevier Science, P.112.

Weick, K. E. (1979). "The Social Psychology of Organizing", Random Heuse" N.Y. Boisot, Max H., “Knowledge Assets”, Oxford University Process, P. 33.

Zuboff, S. (1998). In The Age of The Smart Machine: The Future of Work and Power. Basic Books, N.Y. P.9.

Table 1. The outlines for the methods of the suggested work

\begin{tabular}{|l|l|l|}
\hline Criteria & Structure & Early stages for temporary projects \\
\hline Constructive & Weakly connected & Groups, work teams \\
\hline Responsibility & Unlimited flexibility & Personal, official, and delegated \\
\hline Thinking field & Extended range & Extended range \\
\hline Leadership & Lack of transparency & Dual, transparent \\
\hline Rules \& Regulations & Weakly connected & Consistent \\
\hline Knowledge & Implicit & Clear \\
\hline
\end{tabular}




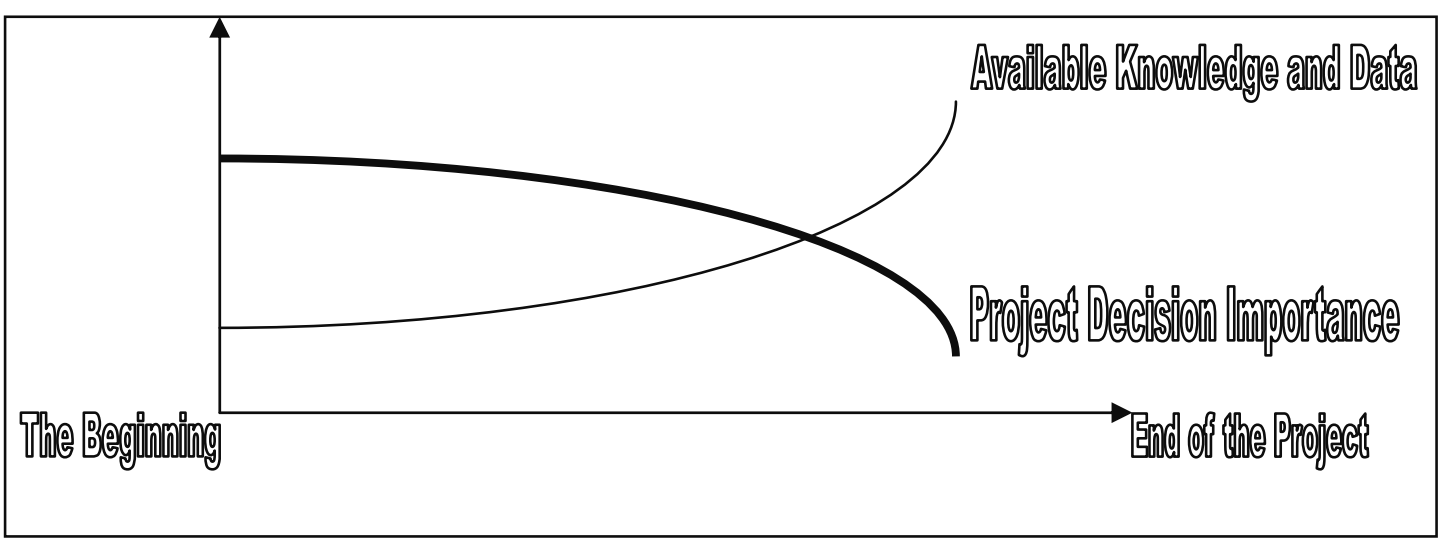

Figure 1. Indicates the outlines of the problem

Source: Mikkelsen, Hans and Jens. The Practice of Creativity, Harper and Row Publishers,Inc. N.Y, 1989.

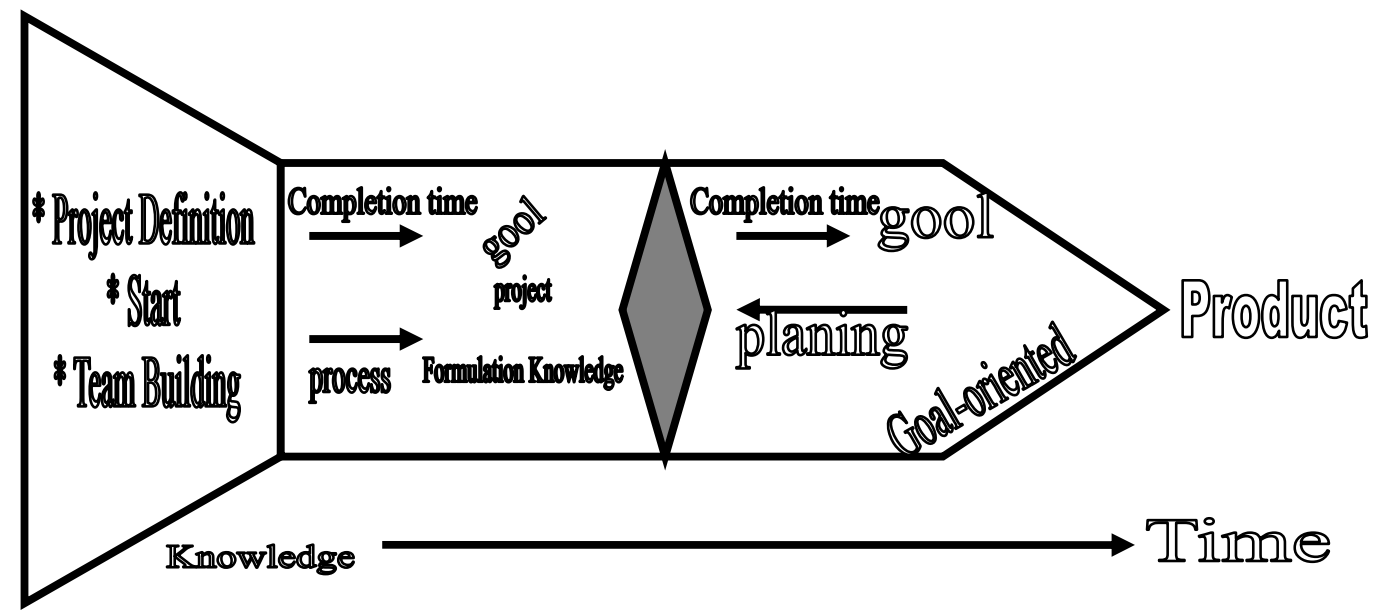

Figure 2. Start-up and implementation of project work

Source: Herald, Henrik:(1995) “KUBUS”, Report N .130, Business School.. P.19.

Hargreavers, Heap, S., (1989) "Rationality in Economics”, Basil Blackwell, Oxford ..P.12. 


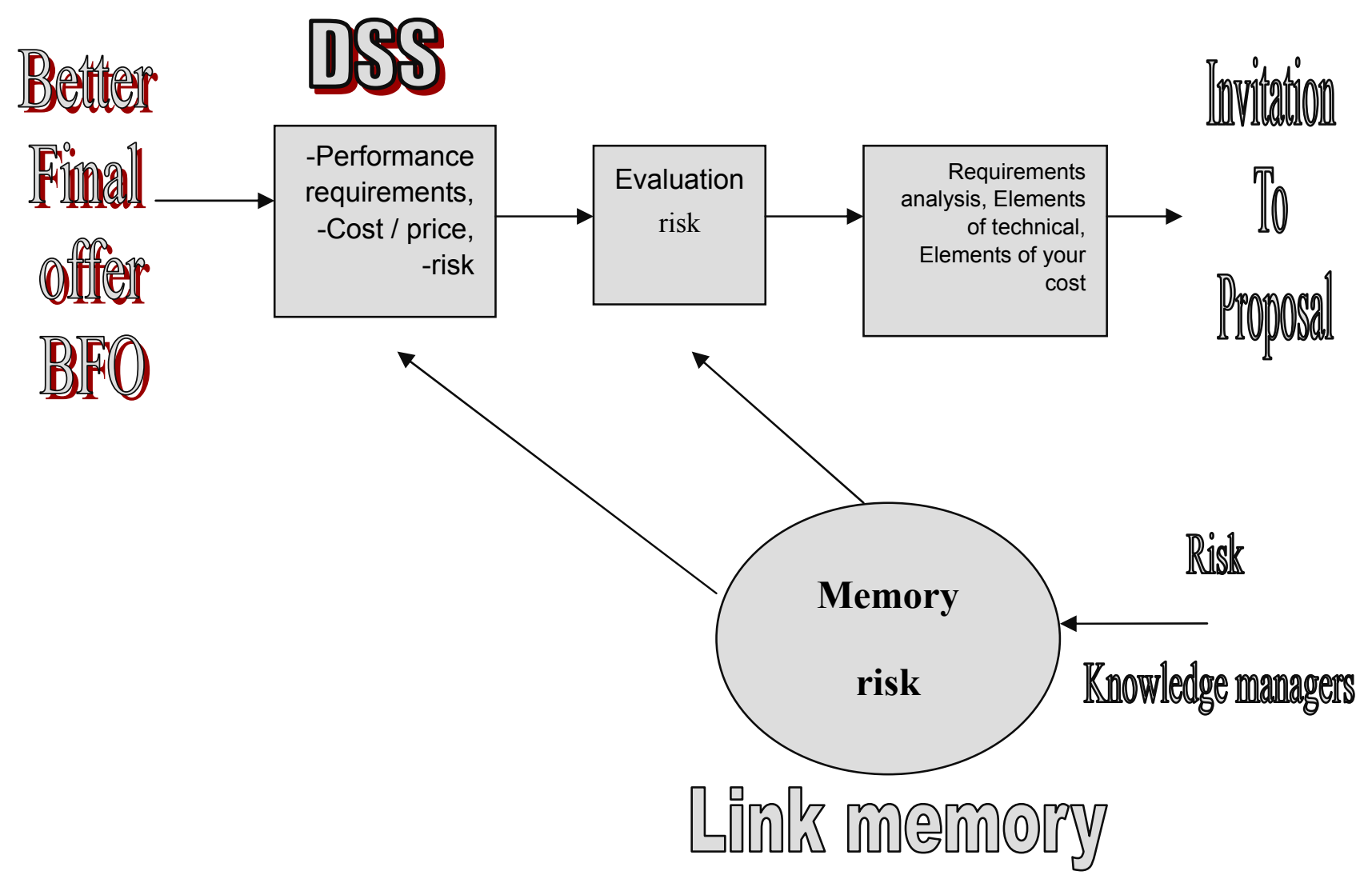

Figure 3. Approach of the Risk Management Operational 